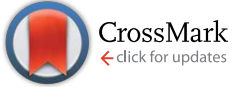

Cite this: RSC Adv., 2017, 7, 9888

Received 23rd December 2016 Accepted 29th January 2017

DOI: $10.1039 / \mathrm{c} 6 \mathrm{ra} 28638 \mathrm{k}$

rsc.li/rsc-advances

\section{Inclusion complexes of norepinephrine with $\beta$-cyclodextrin, 18-crown-6 and cucurbit[7]uril: experimental and molecular dynamics study $\uparrow$}

\begin{abstract}
Suad K. S. Al-Burtomani and FakhrEldin O. Suliman*
The formation of binary and ternary inclusion complexes of norepinephrine, NP, with $\beta$-cyclodextrin ( $\beta C D$ ), cucurbit[7]uril (CB7) and 18-crown-6 (18C6) have been investigated. Fluorescence spectroscopy revealed the enhancement of emission at around $312 \mathrm{~nm}$ from NP in the presence of $\beta C D$. However, in the presence of CB7 and $18 \mathrm{C} 6$ this band was quenched and the spectra exhibited an excimer emission at longer wavelength due to aggregation of guest molecules. The stoichiometry of the inclusion complexes has been investigated by electrospray mass spectrometry (ESI-MS) revealing the presence of binary and ternary complexes of NP with the hosts studied. On the other hand, the solid complexes prepared by lyophilization were characterized by FT-IR, Raman spectroscopy and powder X-ray crystallography. Our data, taken together, clearly suggest that the three hosts form stable complexes with NP. Additionally, we performed molecular dynamics simulations on these complexes in aqueous media for 15-20 ns. The results obtained indicated that hydrophobic forces together with extensive hydrogen bonding are responsible for the stability of these complexes.
\end{abstract}

\section{Introduction}

The fascination imparted by supramolecular systems has inspired researchers to exploit new systems with applications spanning from medicine to nanotechnology. Cyclodextrins, calixarenes and crown ethers have been at the front of these endeavors. However, recently other new systems have emerged in the literature such as cucurbit $[n]$ urils and pillararenes, together with their homologues and derivatives. ${ }^{1-8}$ These molecules have been used as selective hosts for a plethora of guests. Interestingly, the complexes formed between these hosts and their guests were mainly stabilized by weak noncovalent interactions such as van der Waals forces, hydrophobic interactions, hydrogen bonding, and ion-dipole interactions among others. ${ }^{9}$

Molecular recognition by cyclodextrin (CDs), cucurbit $[n]$ urils (CBs) and crown ethers for various guest molecules differs significantly. Cyclodextrins are naturally formed by the action of enzyme cyclodextrin glycosyltransferase on starch to form oligosaccharides with 6, 7 and 8 D-glucopyranose units to form the chiral receptors $\alpha \mathrm{CD}, \beta \mathrm{CD}$ and $\gamma \mathrm{CD}$ (with cavity diameters of 4.7-5.3, 6.0-6.5, and 7.5-8.5 $\AA$ for $\alpha-, \beta$-, and $\gamma-\mathrm{CD}$, respectively). ${ }^{10}$ On the other hand, CBs are formed by condensation of

Department of Chemistry, College of Science, Sultan Qaboos University, Box 36, Al-Khod 123, Oman. E-mail: fsuliman@squ.edu.om; Fax: +968-24141469; Tel: +96824141480

$\dagger$ Electronic supplementary information (ESI) available. See DOI: $10.1039 / \mathrm{c} 6 \mathrm{ra} 28638 \mathrm{k}$ glycoluril with formaldehyde units to form symmetrical achiral CB6, CB7 and CB8 molecules. ${ }^{1,3,4}$ The two openings of CD's cavities are different in size. The wider rim is lined with secondary hydroxyl groups while the narrower one carries primary hydroxyl groups. In case of CBs the two portals are identical in size and both are lined with carbonyl groups.

The presence of well-defined hydrophobic cavities in these two types of hosts has allowed guest molecules insert into them depending on the size and structure of the cavity as well as the size, shape and charge of the guest. Cyclodextrins form three dimensional truncated cones that generally prefer to form noncovalent inclusion complexes with hydrophobic molecules or the hydrophobic parts of a molecule. Cucurbit $[n]$ urils, on the other hand, possess a cylindrical structure and similar to cyclodextrins they encapsulate molecules in their hydrophobic cavity. The carbonyl groups that line the portals of the CBS molecules furnish rich electron sites suitable for hydrogen bonding and electrostatic interactions with guest cations in a fashion similar to crown ethers. The rigid structures and the ability of these host molecules to form stable complexes with guest molecules and ions make them attractive for supramolecular assemblies. However, the major hurdle associated with CBs is their limited solubility in various solvents which hinders their potential to be fully explored. ${ }^{1}$

Crown ethers, on the other hand, are cyclic polyethers bearing mostly oxygen as electron donor atoms. However, when one or more oxygen atoms are replaced by nitrogen or sulfur atoms azacrown ethers and thiacrown ethers are obtained, respectively. ${ }^{11}$ The availability of multiple binding sites coupled 
to the molecule's conformational flexibility allow them to engage in complexation with cations of the alkali and alkaline earth metals, ammonium ion, amines, ionic and polar organic molecules. ${ }^{12,13}$ The stability of the host-guest species of crown ethers and various guest molecules depends on the cavity size, hydrogen bonding and solvation parameters.

It is worth noting here that amongst these three hosts, cyclodextrins are optically active compounds capable of forming diastereomeric pairs by complexation or association with racemic mixtures. Therefore, an arsenal of neutral, cationic and anionic cyclodextrins has been extensively used in chiral chromatography. ${ }^{\mathbf{1 4 - 1 9}}$ However, chiral recognition of small molecules bearing a primary amine moiety near the chiral center by cyclodextrin remains a challenging problem. This is principally due to the formation of flexible complexes with the chiral host molecule. It has been reported that presence of a non-chiral crown ether, such as 18-crown-6, together with the cyclodextrin imparted enantioseparation of some amines that could otherwise not be resolved or are partially resolved by cyclodextrin alone..$^{20-24}$ It is generally believed that chiral recognition in macrocyclic systems is promoted by the rigidity of the system and the bulkiness of the analytes, however, this has not yet been confirmed. Therefore, the role of the crown ethers in the chiral separation remains unraveled.

Host-guest complexation is usually investigated by a portfolio of analytical techniques, such as Fourier transform infrared and Raman spectroscopies, NMR spectroscopy, X-ray crystallography, mass spectrometry, UV-visible and fluorescence spectrophotometry and electrochemical techniques. ${ }^{6,25-30}$ Furthermore, theoretical molecular modeling calculations, such as density functional theory calculations and molecular dynamics are usually used to shed the light on the molecular recognition mechanism and to delineate the structure of these complexes. ${ }^{2,31-36}$

Norepinephrine, NP, is a member of the catecholamine family of compounds known to possess pharmacological activities as neurotransmitters and hormones. It is used to treat cases of low blood pressure because as a stimulant of the sympathetic nervous system it increases the heart rate and blood pressure..$^{37,38}$ Inclusion complexes of some catecholamines, including NP, with various guests have been reported. ${ }^{39,40}$ These studies have suggested that these molecules tend to aggregate in solution, especially at high concentrations and in the presence of host molecules. Ephedrine was reported to exhibit a strong excimer emission when present at concentrations greater than $10^{4} \mathrm{M}$ and when fitted inside the pores of aluminophosphate frameworks, attributed to the $\pi-\pi$ stacking of the aromatic rings of the compound. ${ }^{\mathbf{4 1 , 4 2}}$ Interestingly, pseudoephedrine, a stereoisomer of ephedrine, was reported to exhibit lesser tendency to form supramolecular aggregates. It has been claimed using molecular dynamic simulations that the difference in the stereochemistry of the hydroxyl group lead to conformers of different stability and consequently different aggregations. ${ }^{\mathbf{4 1}}$

The most acceptable mechanism of chiral separations of small aromatic molecules carrying an aromatic amine using a mixture of cyclodextrin and crown ethers is via formation of ternary sandwich compounds. ${ }^{23,43,44}$ In this compound the primary amine is inserted into the $\beta \mathrm{CD}$ cavity and simultaneously interact through its protonated primary group with the crown ether leading to a more stable and rigid molecule.

Prompted by these ideas we embarked on investigating molecular assemblies involving small aromatic compounds bearing amine groups and hosts such as cyclodextrins, crown ether and cucurbiturils. In this work, we decided to compare the interactions of NP with three hosts viz. $\beta \mathrm{CD}, 18 \mathrm{C} 6$ and $\mathrm{CB} 7$ in their binary and ternary mixtures. Our aim is to study the mechanism of interaction of NP with these hosts and whether they cooperatively interact with the guest molecule to form ternary complexes or compete for it. To achieve these goals we studied these complexes in solutions as well as in the solid state using a number of spectroscopic techniques. Moreover, to have a further insight into the mechanism of interaction between NP and these hosts, we used molecular dynamic simulations to study the stability, intermolecular interactions and the mode of inclusion of NP into the nanocavities of these hosts in aqueous media.

\section{Experimental}

\section{General}

Chemicals used in this study were obtained from Sigma-Aldrich and were used without further purification. Solvents of spectroscopy or HPLC grade and ultra-pure water were used for preparation of solutions.

The fluorescence measurements were obtained using LS55 fluorescence Spectrometer (PerkinElmer, USA). The excitation wavelength was set at $270 \mathrm{~nm}$. The electrospray ionization mass spectra, ESI-MS, were collected using Agilent, 6460 Triple quad LC/MS, 1200 Infinity series equipped with electrospray ionization (ESI) interface and operated by MassHunter software. The gas temperature was $300{ }^{\circ} \mathrm{C}$ with flow rate of $5 \mathrm{~L} \mathrm{~min}{ }^{-1}$. The capillary voltage was $3.5 \mathrm{kV}$ and injection volume was $5.00 \mu \mathrm{l}$. The guest and the desired hosts (1-5 mM) were dissolved in ultrapure water and drops of HPLC grade acetonitrile and acetic acid were added before injection.

FT-IR, spectra of guest, hosts and inclusion complexes as well as physical mixtures were obtained using Agilent Cary 630 FTIR spectrometer. The Raman spectra were obtained using XploRA, Horiba Scientific, equipped with a $785 \mathrm{~nm}$ laser (35 $\mathrm{mW}$ ). The laser beam was focused through a $50 \times$ objective lens. The range of vibrational frequencies was from 100 to 3500 $\mathrm{cm}^{-1}$. Five scans were accumulated for each spectrum, with acquisition time $20 \mathrm{~s}$. The Raman measurements were performed at room temperature and atmospheric pressure. All samples were investigated in powder form and no further sample preparation was applied.

The XRD analyses of powder samples were recorded using Panalytical, X' Pert PRO X-Ray Diffraction equipped with copper $\mathrm{X}$-ray source $(45 \mathrm{kV}, 40 \mathrm{~mA})$ and an X Celerator X-ray detector. The powdered samples are analyzed over an angular range of five to seventy degrees $2 \theta$ using a sample spinner to reduce the effects of preferred orientation. 
NMR spectra were obtained on Avance HD III $700 \mathrm{MHz}$ spectrometer (Bruker, Karlsruhe, Germany). All chemical shifts (expressed in ppm scale) are referenced to the solvent signal. Phase sensitive two-dimensional rotating frame nuclear overhauser enhancement correlation (2D-ROESY) experiment were carried out using $180 \times-180 \times$ pulses for spin lock to suppress TOCSY artifacts. Solutions were prepared in $\mathrm{D}_{2} \mathrm{O}$ and drops of deuterated acetic acid were used to adjust $\mathrm{pH}$ of the solutions prior to measurements.

\section{Preparation of the solid inclusion complexes}

An appropriate amount of the 18C6, CB7, $\beta \mathrm{CD}$ and NP were dissolved in $20 \mathrm{ml}$ water to make a concentration of $15 \mathrm{mM}$ of each (few drops of $\mathrm{HCl}(1 \mathrm{M})$ were added in the case of $\mathrm{CB}$ [7] to assist dissolution). Mixtures of solutions of NP in presence of individual hosts were prepared to form binary complexes. Additionally, mixtures of NP with $\beta C D$ in presence of $18 \mathrm{C} 6$ and CB7 to form ternary complexes were also prepared. The solutions were inserted into a shaker-incubator (IKA KS 4000i Control Incubating Shaker, Cole-Parmer) for $48 \mathrm{~h}$ at $40{ }^{\circ} \mathrm{C}$. The inclusion complexes solutions were removed and filtered and immediately submitted to the freeze dryer (Lyo Quest, Telstar) for 72 hours. The solid inclusion complexes obtained were kept desiccated at $-4{ }^{\circ} \mathrm{C}$ for further investigation.

\section{Fluorescence measurements}

Sodium acetate/acetic acid buffer of pH 5.0 was used for the preparation of all aqueous solutions. Series of solutions with constant concentration of NP and different concentrations of hosts ( $\beta \mathrm{CD}, 18$-crown-6 and $\mathrm{CB}[7])$ were prepared. The concentration of NP solution was maintained at $3.5 \times 10^{-6} \mathrm{M}$ while that of the host molecules viz. $\beta$-CD and 18-crown- 6 were varied from $1.0 \mathrm{mM}$ to $15 \mathrm{mM}$. The concentration of $\mathrm{CB} 7$, on the other hand, was varied from 0.01 to $0.1 \mathrm{mM}$. All experiments were carried out at room temperature.

\section{Molecular dynamic calculations}

The chemical structure of hosts and the guest are shown in Scheme 1 . The initial geometry of NP and $18 \mathrm{C} 6$ were optimized using DFT-B3LYP method using 6-31G* basis set. On the other hand, the structures of $\beta C D$ and $\mathrm{CB} 7$ were extracted from the crystallographic parameters provided by the Structural Data Base System of the Cambridge Crystallographic Data Center and were optimized by minimizing their energy using PM7 semiempirical method using MOPAC 2012 (http://openmopac.net). ${ }^{45}$

The molecular dynamics (MD) simulations were carried out using the Desmond molecular simulations package, as distributed by Schrodinger-2015 suite of programs. ${ }^{46,47}$ The OPLS_2005 all-atom force field with explicit solvent (TIP3P water model) were used throughout the calculations. Simulations were run with periodic boundary conditions, in an orthorhombic box with the solute placed in the middle at $20 \AA$ distance from each of the boxes edges. The SHAKE algorithm was used to constrain covalent bonds between hydrogen and heavy atoms. Long-range electrostatic interactions were dealt with using the Ewald smooth particle mesh (PME) method. ${ }^{48}$

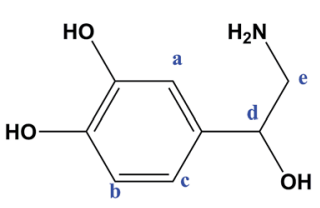

(a)

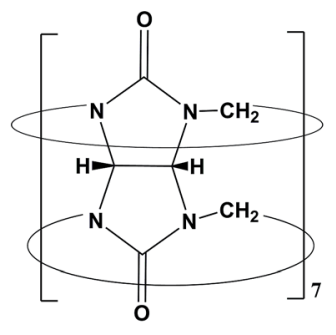

(c)

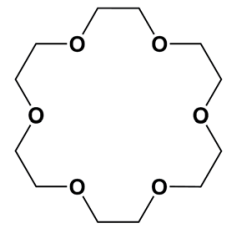

(b)

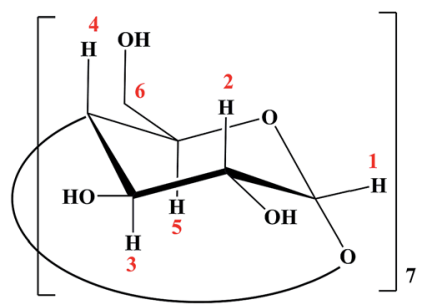

(d)
Scheme 1 Structure of guest and hosts. (a) NP (b) $18 C 6$ (c) CB7 (d) $\beta C D$.

The solvated molecules were subjected to sequential restraint solvent-solute minimizations and short MD simulations on NVT-NPT ensembles (as implemented in the default relaxation protocol in Desmond) coupled to Berendsen thermostat. Finally the production run was NPT run at $300 \mathrm{~K}$ and 1 bar. The simulations were then analyzed by the "simulation event analysis" module in Schrodinger 2015 suit.

\section{Results and discussion}

\section{Fluorescence study}

The fluorescence spectrum of NP is characterized by a peak at around $312 \mathrm{~nm}$ when excited at $270 \mathrm{~nm}$. This band is ascribed to the locally excited state involving $\pi-\pi^{*}$ transition. As Fig. 1a shows, a remarkable increase in the fluorescence intensity of this band is observed upon incremental additions of $\beta C D$ to an aqueous solution of NP. Moreover, the increase in fluorescence intensity is accompanied by a slight shift of the fluorescence maximum $(\sim 5 \mathrm{~nm})$ to the blue region. These results indicate that NP is experiencing an environment different from the bulk water suggesting that it enters the cavity of the host cyclodextrin. The enhancement of the fluorescence of NP upon inclusion is due to suppression of non-radiative decay pathways as rotations of the molecule around a single bond are minimized. Insertion of the catechol moiety into nanocavity of host molecules is also accompanied by hydrogen bonding interaction between the rim hydroxyl groups and the polar groups on NP. ${ }^{39,40}$

We also examined the effect of addition of 18C6 to an aqueous solution of NP to investigate the influence of interaction of amine-group with the crown ether on the fluorescence behavior of this molecule. The results in Fig. 1b show that the emission spectra of NP in presence of 18C6 exhibit a different behavior. Interestingly, the intensity of the peak at $312 \mathrm{~nm}$ started to decrease continuously with an increase in 18C6 concentration. Additionally, a feeble band at $425 \mathrm{~nm}$ started to 
(a)

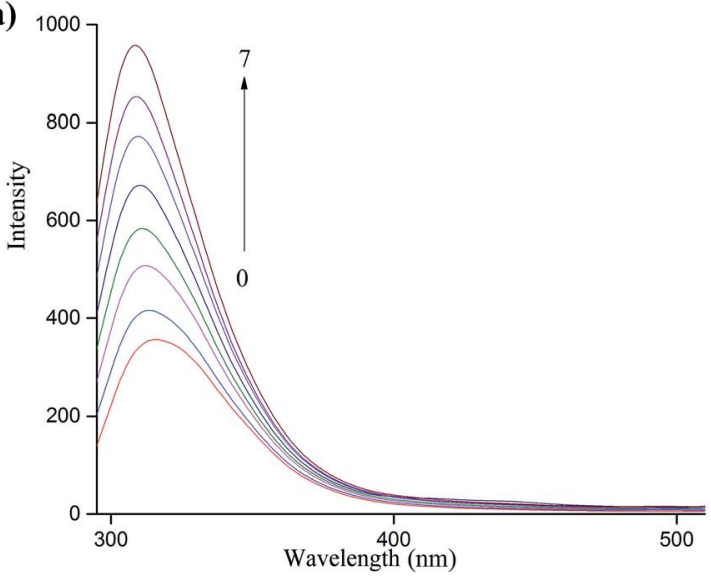

(c)

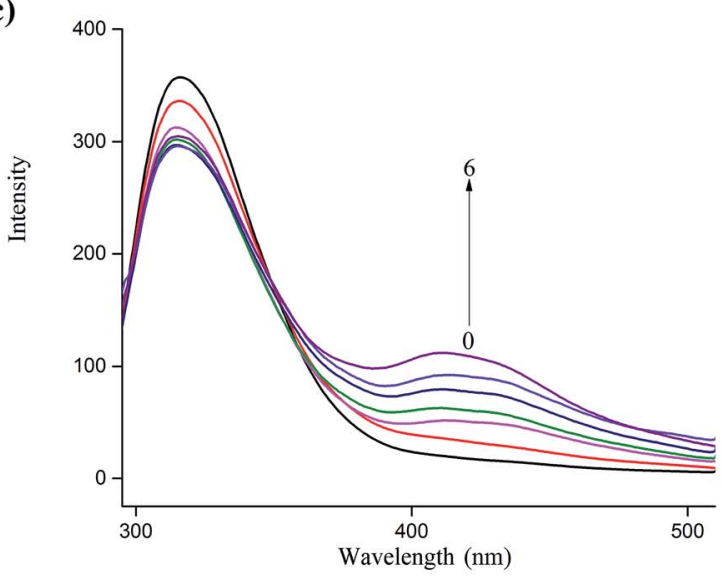

(b)

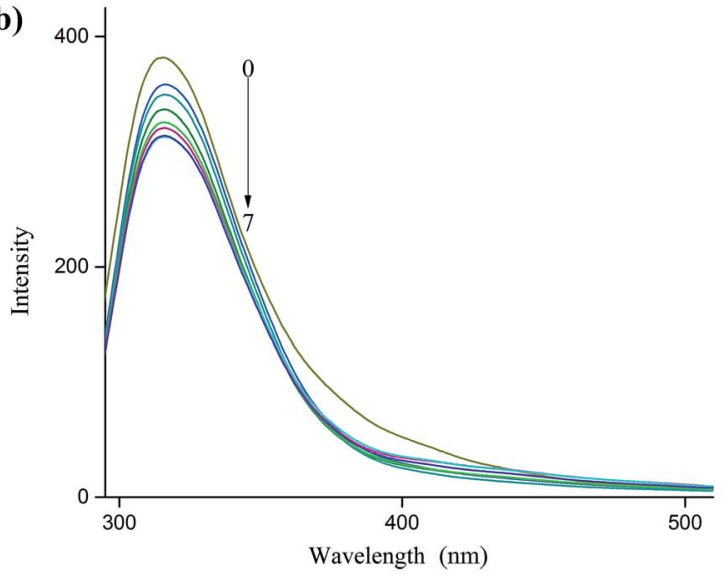

(d)

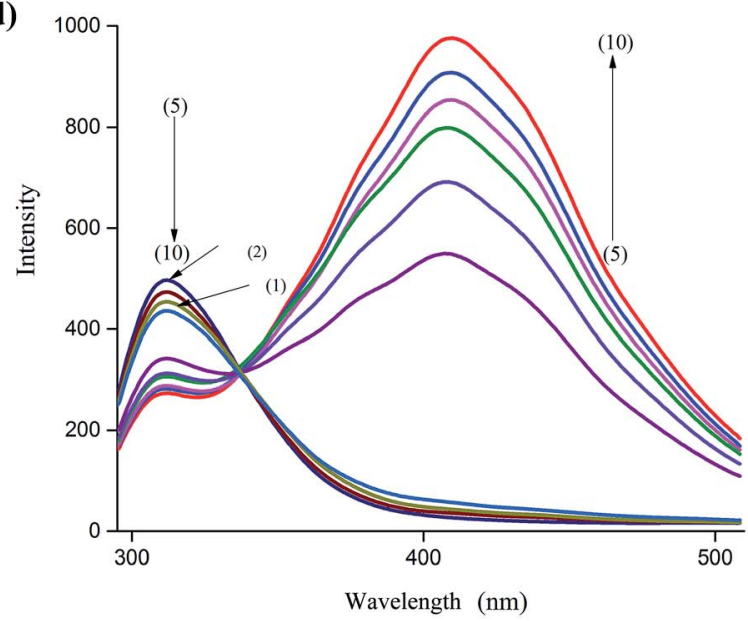

(e)

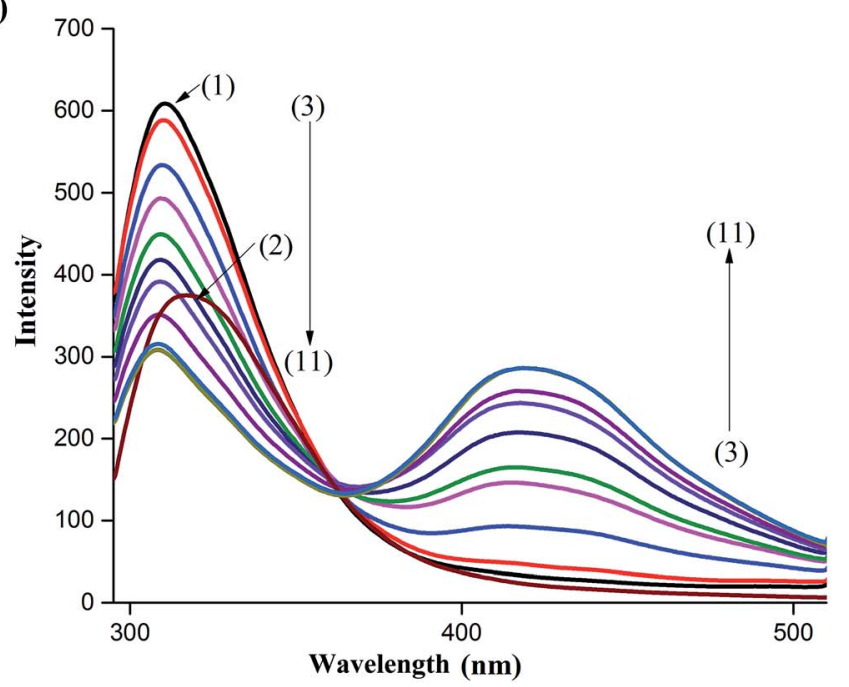

Fig. 1 (a) Fluorescence spectra of (0) NP, $2.5 \times 10^{-6} \mathrm{M}$ with increasing concentration of $\beta C D$ (1) $0.5 \mathrm{mM}$...(7) $14 \mathrm{mM} \mathrm{NP}-\beta C D$. (b) Fluorescence spectra of (0) NP, $2.5 \times 10^{-6} \mathrm{M}$ with increasing concentration of $18 \mathrm{C} 6$ (1) $0.5 \mathrm{mM} \ldots$..(7) $14 \mathrm{mM} \mathrm{NP}-18 \mathrm{C} 6$. (c) Fluorescence spectra of (0) NP, $3.5 \times$ $10^{-6} \mathrm{M}$ with increasing concentration of CB7 (1) $0.01 \mathrm{mM}$...(7) $0.09 \mathrm{mM} \mathrm{NP}-\mathrm{CB} 7$. (d) Fluorescence spectra of (1) NP, $3.5 \times 10^{-6} \mathrm{M}$ (2) NP, $3.5 \times$ $10^{-6} \mathrm{M}+3 \mathrm{mM} \beta C D$ with increasing concentration of $18 \mathrm{C} 6$ (3) $0.3 \mathrm{mM} \ldots$.. (10) $6.5 \mathrm{mM} \mathrm{NP}-\beta C D-18 \mathrm{C} 6$. (e) Fluorescence spectra of (2) NP, $3.5 \times$ $10^{-6} \mathrm{M}$ (1) NP, $3.5 \times 10^{-6} \mathrm{M}+3 \mathrm{mM} \beta \mathrm{CD}$ with increasing concentration of CB7 (3) $0.4 \mu \mathrm{M}$ to (10) $8.0 \mu \mathrm{M}$. 
grow with the appearance of an isoemissive point at around $370 \mathrm{~nm}$ clearly suggesting the formation of two species. Similar results were obtained upon incremental additions of $\mathrm{CB} 7$ to NP aqueous solution as illustrated in Fig. 1c. In presence of $\mathrm{CB} 7$ the peak at $425 \mathrm{~nm}$ grows much higher in intensity compared to when 18C6 is added. The long wavelength band is ascribed to the excimer emission as have been reported for NP and similar molecules. ${ }^{39,40}$ This band is believed to originate from the aggregation of NP molecules induced by interaction with the host molecules. The molecular aggregation quenches the fluorescence of the monomer band and results in a new emission band at longer wavelength.

In chiral separations of primary amines by cyclodextrins it has been reported that addition of $18 \mathrm{C} 6$ to the mobile phase imparts improved resolutions in many instances. ${ }^{23,43,49}$ These phenomena have been explained on the basis of formation of a ternary complex between the amine, CD and 18C6. In this work we studied the effect of $18 \mathrm{C} 6$ on the fluorescence of NP- $\beta \mathrm{CD}$ inclusion complex by adding the crown ether to a mixture of NP (3.5 $\mu \mathrm{M})$ and $\beta \mathrm{CD}(3 \mathrm{mM})$. Initially additions of $18 \mathrm{C} 6$ resulted in a decrease in the emission intensity of the short-wavelength band together with a slow growth of the long-wavelength band up to addition of $0.5 \mathrm{mM}$ concentration of 18C6 (Fig. 1d). Interestingly, with further additions of 18C6 a remarkable enhancement of fluorescence intensity of the longer-wavelength band is observed with the appearance of vibrational details.

CB7 is a host that interacts strongly with positively charged ions. It resembles crown ethers in possessing electron rich portals capable of attracting positively charged species. Moreover, the barrel shaped molecule is characterized by possessing a hydrophobic cavity similar to cyclodextrins. The main difference between the two cavities resides in the fact that CBs possess portals that are significantly electron rich. In addition, the inner surface of CBs is also negative. Therefore, the affinity of CB7 to charged species is noticeably high compared to CDs. ${ }^{50}$ Addition of aliquots of $\mathrm{CB} 7$ to an aqueous solution of NP- $\beta C D$ $([\beta C D]=3 \mathrm{mM})$ resulted in quenching of the shorterwavelength band accompanied by a gradual increase of the longer-wavelength band as shown in Fig. 1e. Interestingly, the shorter-wavelength band underwent further blue shift. These results are similar to those observed for NP- $\beta C D-18 C 6$ system.

$\beta C D$ form complexes that aggregate via formation of head-tohead, head-to-tail and tail-to-tail dimers. ${ }^{51}$ These dimers are stabilized by strong hydrogen bonding that could also involve water molecules in the inter-dimer space. It has been reported that the nature of guest molecules encapsulated into the cavity of the host affects greatly the structure of CD aggregates and the ensuing crystals. For instance, small guest molecules were found to result in herring-bone packed monomer crystals, whereas moderate to large gusts crystallizes through head-tohead inclusion complexes dimers. ${ }^{52,53}$ The later phenomena is greatly enhanced by the extensive hydrogen bonding between the secondary hydroxyl-groups lining the wider CD cavity and it also involve interactions of the polar groups of the guest with each other and with the hydroxyl groups of the CD. For NP- $\beta C D$ and in presence of $18 \mathrm{C} 6$ and CB7 the formation of head-to-head and tail-to-tail aggregates is possible. The ammonium group interacts strongly with $18 \mathrm{C} 6$ and is also expected to interact with CB7. Then insertion of the catechol group inside the CD cavity from the narrow side will allow head-to-head dimers to form, however, penetration of the catechol group from the wider sider of the CD may result in tail-to-tail dimer.

(a)

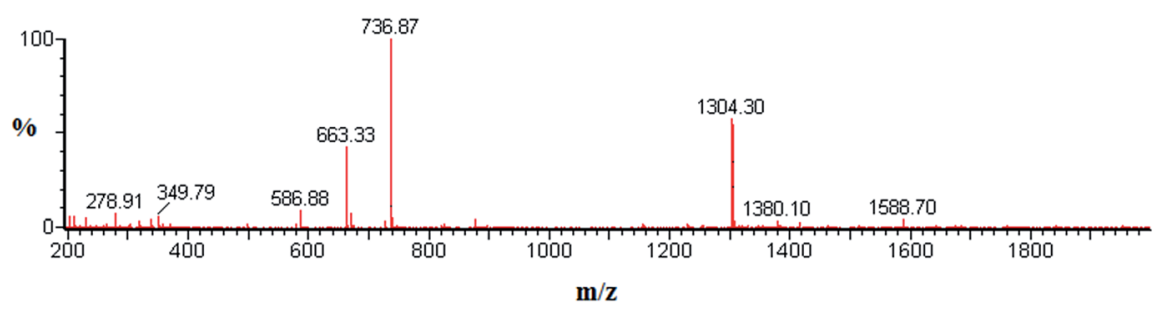

(b)

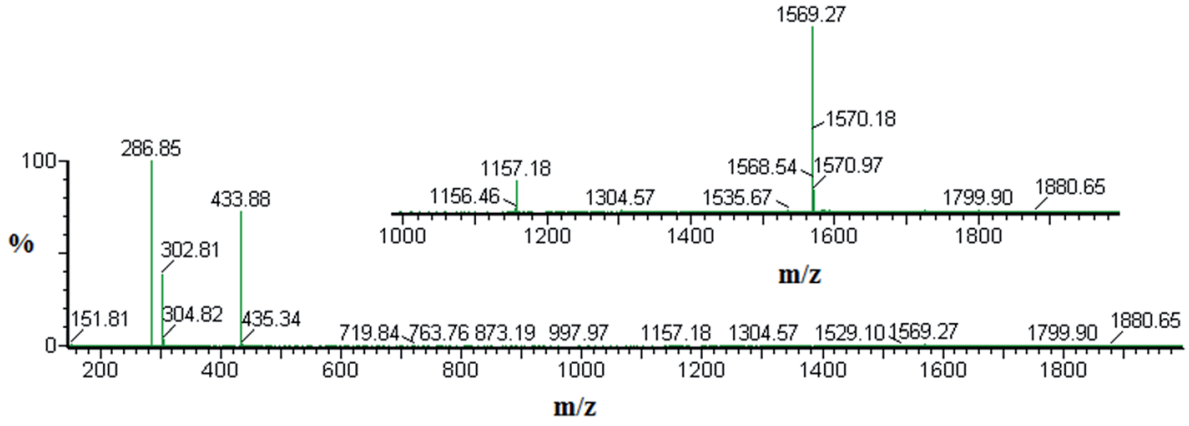

Fig. 2 ESI-MS spectra of (a) NP- $\beta C D$ (b) NP- $\beta C D-18 C 6$. 


\section{ESI-MS}

We used ESI-MS to investigate the stoichiometry of the various species involved in complexation between NP and the three hosts included in this study. The ESI-MS spectra are recorded in the positive mode and examples of them are displayed in Fig. 2 and the results are summarized in Table 1 . The formation of NP- $\beta C D$ complexes is clearly evident from the singly charged and doubly charged species $[\mathrm{NP}-\beta \mathrm{CD}+\mathrm{H}]^{+},[2 \mathrm{NP}-\beta \mathrm{CD}+2 \mathrm{H}]^{2+}$ and $[\mathrm{NP}-\beta \mathrm{CD}+\mathrm{Na}+\mathrm{H}]^{2+}$ at $m / z 1304,737$ and 663, respectively as shown in Fig. 2a. The guest molecule is represented by the singly charged ions at $\mathrm{m} / \mathrm{z} 169.8$ and 338.8 associated with the monomer $[\mathrm{NP}+\mathrm{H}]^{+}$and the dimer $[2 \mathrm{NP}+\mathrm{H}]^{+}$, respectively. These results indicate the possibility of dimerization of NP in solution as well as in the gas phase.

The ESI-MS results of NP- $\beta$ CD-18C6 are characterized by intense signals that correspond to various singly charged ion complexes of $18 \mathrm{C} 6$ such as $[18 \mathrm{C} 6+\mathrm{Na}]^{+}$at $\mathrm{m} / z$ 286.9, and [18C6 $+\mathrm{K}]^{+}$at $m / z 302.8$ (Table 1 ). The most striking finding in these spectra is the emergence of a singly charged species at $\mathrm{m} / \mathrm{z}$ 1569.2 (Fig. 2b) attributed to the ternary complex [NP- $\beta \mathrm{CD}-$ $18 \mathrm{C} 6+\mathrm{H}]^{+}$ion. Additionally, a doubly charged ion at $m / z 877$ is believed to be associated with $[2 \mathrm{NP}-\beta \mathrm{CD}-18 \mathrm{C} 6+2 \mathrm{H}]^{2+}$. Furthermore, the interaction between NP and 18C6 is confirmed by the peak at $m / z 433.8$ for $[\mathrm{NP}-18 \mathrm{C} 6+\mathrm{H}]^{+}$ion.

The ESI-MS spectrum of NP-CB7 complex is presented in Fig. S1. $\dagger[\mathrm{NP}-\mathrm{CB} 7+\mathrm{H}]^{+}$ions show a signal at $\mathrm{m} / z 1333$ confirming the formation of a $1: 1$ inclusion complex between NP and CB7. Moreover, the interaction of dimer 2NP with $\mathrm{CB} 7$ is represented by a peak at $m / z 751$ which correspond to [2NP-CB7 $+2 \mathrm{H}]^{2+}$ ion. On the other hand, the cluster peak at $\mathrm{m} / \mathrm{z} 1319$ in Fig. $\mathrm{S} 2 \dagger$ was found to match with the doubly charged species

Table 1 ESI-MS results for the inclusion complexes of NP with various hosts

\begin{tabular}{ll}
\hline$m / z$ & Species \\
\hline $\mathbf{N P}-\boldsymbol{\beta C D}$ & \\
1304.30 & {$[\mathrm{NP}-\beta \mathrm{CD}+\mathrm{H}]^{+}$} \\
663.33 & {$[\mathrm{NP}-\beta \mathrm{CD}+\mathrm{Na}+\mathrm{H}]^{2+}$} \\
736.87 & {$[2 \mathrm{NP}-\beta \mathrm{CD}+2 \mathrm{H}]^{2+}$} \\
590.0 & {$[\beta \mathrm{CD}+2 \mathrm{Na}]^{+}$} \\
338.85 & {$[2 \mathrm{NP}+\mathrm{H}]^{2+}$} \\
169.80 & {$[\mathrm{NP}+\mathrm{H}]^{+}$} \\
& \\
$\mathbf{N P}-\boldsymbol{\beta C D}-\mathbf{1 8 C 6}$ & \\
1569.27 & {$[\mathrm{NP}-\beta \mathrm{CD}-18 \mathrm{C} 6+\mathrm{H}]^{+}$} \\
1157.18 & {$[\beta \mathrm{CD}+\mathrm{Na}]^{+}$} \\
877.04 & {$[2 \mathrm{NP}-\beta \mathrm{CD}-18 \mathrm{C} 6+2 \mathrm{H}]^{2+}$} \\
433.88 & {$[\mathrm{NP}-18 \mathrm{C} 6+\mathrm{H}]^{+}$} \\
302.81 & {$[18 \mathrm{C} 6+\mathrm{K}]^{+}$} \\
286.85 & {$[18 \mathrm{C} 6+\mathrm{Na}]^{+}$} \\
& \\
$\mathbf{N P}-\boldsymbol{\beta C D}-\mathbf{C B} 7$ & {$[\mathrm{NP}-\mathrm{CB} 7+\mathrm{H}]^{+}$} \\
1333 & {$[2 \mathrm{NP}-\mathrm{CB} 7-\beta \mathrm{CD}+2 \mathrm{H}]^{2+}$} \\
1319 & {$[\mathrm{CB} 7+\mathrm{H}]^{+}$} \\
1163 & {$[\beta \mathrm{CD}+\mathrm{H}]^{+}$} \\
1135 & {$[2 \mathrm{NP}-\mathrm{CB} 7+2 \mathrm{H}]^{2+}$} \\
751 &
\end{tabular}

$[2 \mathrm{NP}-\mathrm{CB} 7-\beta \mathrm{CD}+2 \mathrm{H}]^{2+}$. Hence the ESI-MS spectra clearly suggest that dimer species of NP are present either freely or complexed with the hosts. It has been argued that the presence of inclusion species in the gas phase could indicate their possible existence in the solution. The driving force for complex formation stems from the hydrophobic interactions leading to the formation of inclusion complexes in solution stabilized by the favorable thermodynamic balance of enthalpy and entropy. In ESI-MS, the release of guest molecules from the host cavity is favored as entropy and enthalpy oppose each other. ${ }^{54}$ Nevertheless, complexes between guest and host are mainly stabilized by hydrogen bonding and other weaker forces such as van der Waals forces. Hence protonated groups such as the primary amine in NP are expected to enhance the chances of preservation of inclusion complexes in the gas phase supported by a strong network of hydrogen bonding interaction compared to those in the solution. Therefore, the presence of all species presented in Table 1 suggests that these molecules are actually present in solution which is in line with the fluorescence data presented above.

\section{FTIR spectroscopy}

In this study binary inclusion complexes of NP with $\beta C D, C B 7$ and $18 \mathrm{C} 6$ as well as ternary inclusion complexes of NP with $\beta \mathrm{CD}$ in presence of $\mathrm{CB} 7$ or 18C6 were obtained by freeze drying techniques. The FTIR spectra of pure guest and hosts are shown in Fig. S3† whereas those of binary complexes are shown in Fig. 3a. $\beta C D$ is characterized by peaks at 1021, 1074 and 1151 $\mathrm{cm}^{-1}$ assigned to the $\mathrm{C}-\mathrm{C}, \mathrm{C}-\mathrm{O}$ stretching modes and $\mathrm{C}-\mathrm{O}-\mathrm{C}$ glycosidic asymmetric vibrations. ${ }^{51,55}$

Assignment of NP vibrational signals was based on literature. ${ }^{56}$ The finger-print region of $650-1260 \mathrm{~cm}^{-1}$ involves mainly bending and torsional vibrations of aromatic, $-\mathrm{CH}_{2}$ and $\mathrm{CNH}$ groups. The peaks at 1356 and $1590 \mathrm{~cm}^{-1}$ correspond to aromatic stretching vibrations with contributions from $-\mathrm{CH}_{2}$ and $\mathrm{OH}$ bending modes. By inspection of the FTIR spectra of NP and $\beta C D$ one observe a large degree of overlap between the peaks of the two compounds. This indeed complicates interpretation of spectra of the inclusion complexes formed between the two compounds.

Clearly, the spectrum of NP- $\beta \mathrm{CD}$ complex resembles to a great extent the spectrum of $\beta C D$. However, few differences can be pointed out. For instance, in NP- $\beta C D$ the band at 3266 $\mathrm{cm}^{-1}$ was shifted to $3248 \mathrm{~cm}^{-1}$. Most NP bands disappeared in the complex spectrum indicating that NP is deeply encapsulated into the host cavity.

The FTIR spectrum of CB7 (Fig. S3 $\dagger$ ) shows a broad and strong band at $3404 \mathrm{~cm}^{-1}$ assigned to $\mathrm{NH}$-stretching vibration in addition to a band at $2933 \mathrm{~cm}^{-1}$ attributed to $\mathrm{CH}$ stretching vibration. The bands become broader and shifted in NP-CB7 complex is indicative of the involvement in intermolecular interactions. Moreover, the carbonyl stretching mode appears at $1713 \mathrm{~cm}^{-1}$ in CB7 is slightly shifted to $1720 \mathrm{~cm}^{-1}$ in the NP-CB7 complex. This is also an indication of formation of hydrogen bonding between the guest and the host molecules. The band at $1468 \mathrm{~cm}^{-1}$ is assigned to the $\mathrm{C}-\mathrm{N}$ stretching mode. This band 
(a)

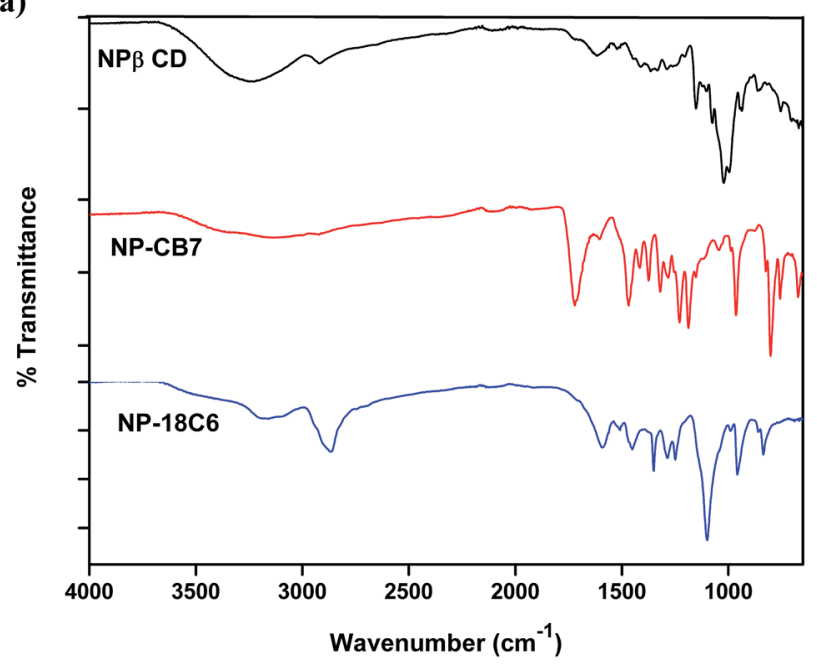

(b)

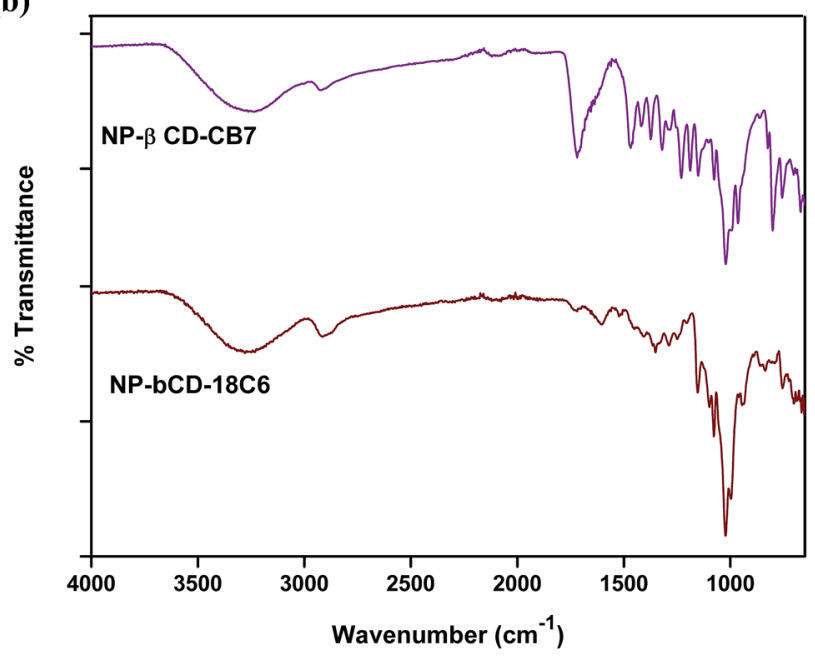

Fig. 3 FT-IR spectra of (a) binary complexes (b) ternary complexes of $N P-\beta C D$ with $C B 7$ and $18 C 6$.

and all other bands below $1400 \mathrm{~cm}^{-1}$ are slightly modified by the presence of NP. In addition, it was observed that peaks pertinent to NP in this region have vanished. Again these results suggest that there are host-guest interactions between NP and CB7 that possibly lead to the formation of stable inclusion complex.

In case of NP-18C6, the spectrum of the complex also reveals that there is an interaction between NP and 18C6 regardless of the subtle differences between the spectra of host and complex. One can conclude also here that the differences in spectra mean that a complex is formed between the two compounds.

Ternary complex NP- $\beta C D-18 C 6$ spectrum, on the other hand, is dominated by $\beta C D$ signals (Fig. $3 \mathrm{~b}$ ). Surprisingly, the main feature of this spectrum is the disappearance of the characteristic peak of $18 \mathrm{C} 6$ at $2862 \mathrm{~cm}^{-1}$. This peak was slightly shifted in NP-18C6 spectrum, but completely vanished in the ternary complex. A similar trend was observed when other crown ethers such as aza-18C6 were used with NP and $\beta C D$ to form ternary complexes (results not shown). As in binary complexes, the peaks related to NP have completely disappeared in this complex as well. These results strongly suggest the presence of intermolecular interaction involving the three molecules.

The FTIR spectrum of NP- $\beta C D-C B 7$ is also shown in Fig. $3 \mathrm{~b}$. It is apparent from this figure that the spectrum of NP- $\beta C D-$ CB7 system contains bands that correspond to the two hosts, while those characteristic bands of NP have been diminished. For example, the signals at $1719 \mathrm{~cm}^{-1}$ and $1468 \mathrm{~cm}^{-1}$ are similar to those present in NP-CB7 spectrum. As in the above cases, the huge overlap between signals makes the identification of unique features difficult. However, the variations observed in the spectra evidently suggest that a different spectrum is obtained compared to the individual binary complexes spectrum. It is worth mentioning here that using this vibrational tool alone it is not possible to ascertain whether or not binary complexes of NP with individual host molecule are present mixed or the ternary complex is formed.

\section{Raman spectroscopy}

Raman spectroscopy is a complementary vibrational technique that enables investigation and characterization of inclusion complexes. The differences in vibrational frequencies position and intensity provide important clues to formation of inclusion complexes of guest molecules like NP with host molecules. The Raman spectra of NP as well as that of host $\beta C D$ in neat solids are given in Fig. 4. NP Raman spectrum is characterized by sharp intense peaks in the range $500-1700 \mathrm{~cm}^{-1}$. The strong peak at $1617 \mathrm{~cm}^{-1}$ is assigned to $-\mathrm{NH}_{2}$ bending vibration. On the other hand, the band at $1283 \mathrm{~cm}^{-1}$ corresponds to $\mathrm{CH}_{2}$ stretching vibration; however, it is also believed that this peak is coupled to $\mathrm{CO}$ stretching vibration. ${ }^{57}$ Moreover, the strong

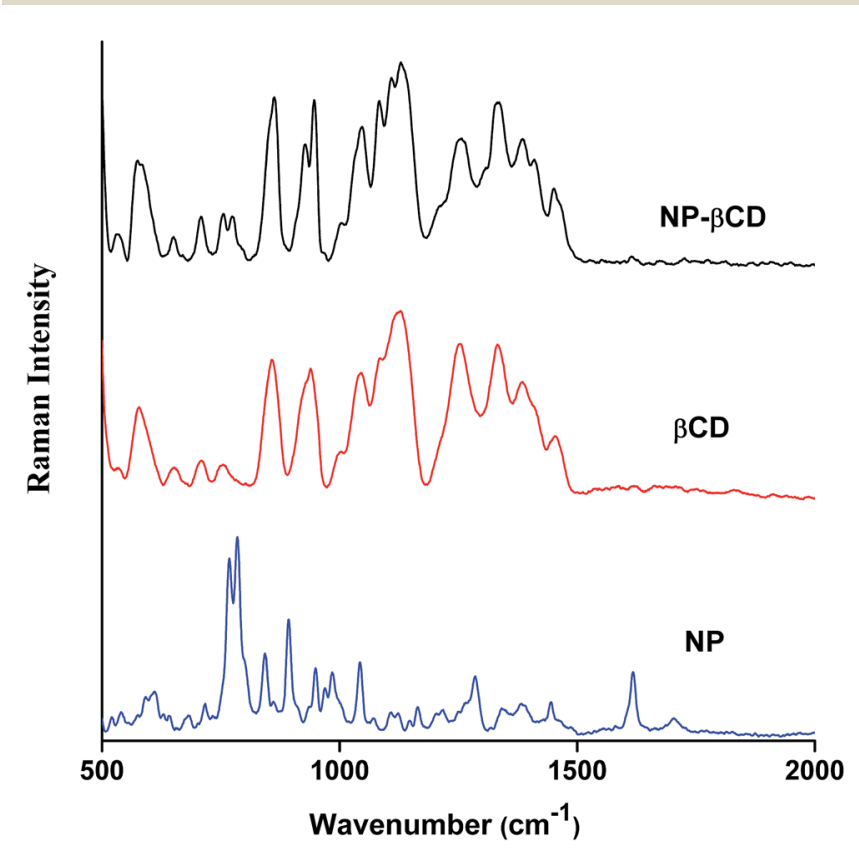

Fig. 4 FT-Raman spectra of NP, $\beta C D$ and $N P-\beta C D$ freeze dried complex. 
bands at 891 and $846 \mathrm{~cm}^{-1}$ are attributed to $\mathrm{CH}_{2}$ and $\mathrm{NH}_{2}$ bending vibrations, respectively. The most significant peaks of $\mathrm{NP}$ are those located at 783 and $767 \mathrm{~cm}^{-1}$ originating due to catecholic ring breathing. The band at $783 \mathrm{~cm}^{-1}$ has also been reported to have contributions from $\mathrm{CH}-\mathrm{NH}$ in plane bending vibrations.

The Raman spectrum of NP- $\beta C D$ inclusion complex prepared by freeze drying methods is also shown in Fig. 4. It is mainly dominated by $\beta C D$ vibrational bands especially in the region 500-1500 $\mathrm{cm}^{-1}$. Vibrational Raman spectroscopy is known to be very sensitive to non-covalent intermolecular interactions that are usually encountered in inclusion complexes. ${ }^{58,59}$ As can be seen from Fig. 4, $\beta \mathrm{CD}$ bands are all enhanced in intensity upon complexation with NP and as well experienced slight shifts. It is also notable that all NP vibrations have vanished except for the two most prominent peaks at 783 and $767 \mathrm{~cm}^{-1}$ which were greatly reduced in intensity and shifted to 771 and $751 \mathrm{~cm}^{-1}$, respectively. Moreover, the peak at $1617 \mathrm{~cm}^{-1}$ is also reduced in intensity and shifted to $1603 \mathrm{~cm}^{-1}$. These alterations in the Raman signals of NP are in line with the formation of strong intermolecular interactions when the guest enters the cavity of the host. Additionally, the Raman bands associated with the $\mathrm{C}-\mathrm{O}$ stretching modes of glycosidic linkage of $\beta C D$ at 1127, 1081, 1043, 944 and $925 \mathrm{~cm}^{-1}$ have been evolved and became well separated from each other due to complexation. These bands are known to be very sensitive to the presence of guest molecules. ${ }^{\mathbf{5 8 , 5 9}}$

Fig. 5 shows the Raman spectra of $\mathrm{CB} 7$ and NP-CB7 inclusion complex prepared by freeze-drying. The bands at 830 and $897 \mathrm{~cm}^{-1}$ represent deformation of CB7 ring whereas the bands at 1377 and $1418 \mathrm{~cm}^{-1}$ are assigned to symmetric and asymmetric C-N stretching vibrations. ${ }^{60}$ The carbonyl bands appear at 1755 and $1731 \mathrm{~cm}^{-1}$. In the inclusion complex of NP-CB7 all peak positions pertinent to $\mathrm{CB} 7$ remained almost unchanged except for the two peaks at 1755 and $1731 \mathrm{~cm}^{-1}$ associated with the carbonyl peak which were replaced by a single peak of

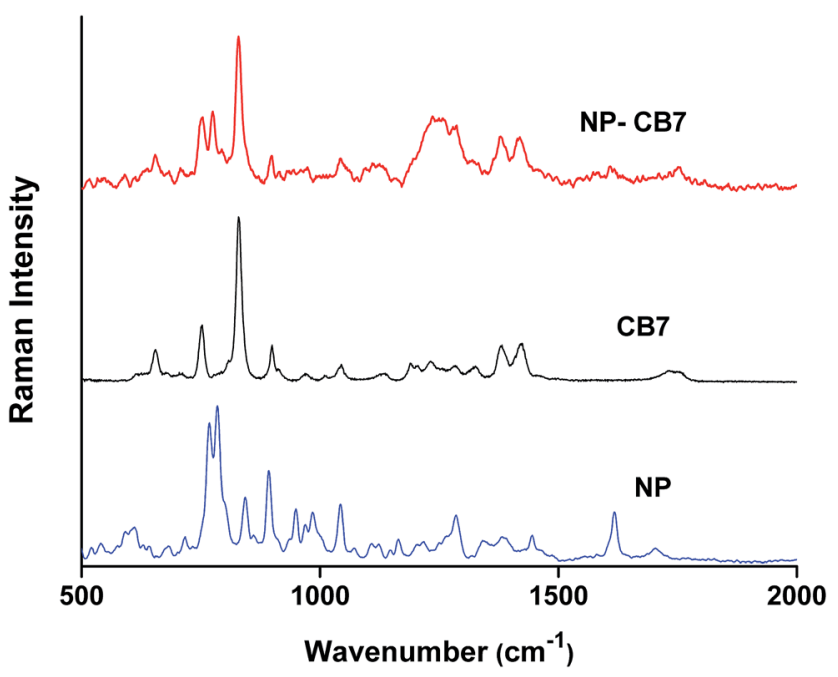

Fig. 5 FT-Raman spectra of NP, CB7 and NP-CB7 freeze dried complex.

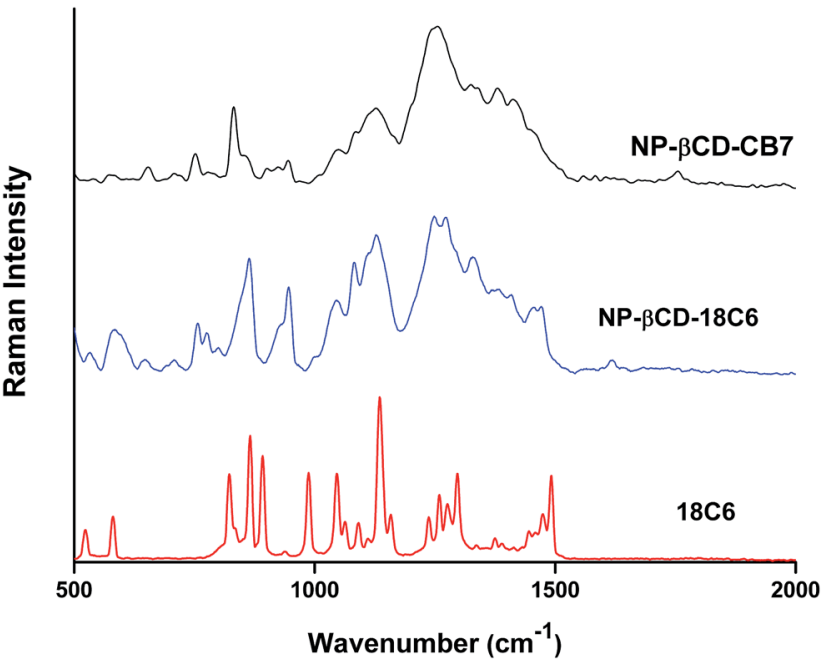

Fig. 6 FT-Raman spectra of $18 C 6, N P-\beta C D-18 C 6$ and NP- $\beta C D-C B 7$ freeze dried complexes.

diminished intensity at $1744 \mathrm{~cm}^{-1}$ in the complex. Generally, CB7 peaks, unlike $\beta C D$, are all decreased in intensity compared to pure CB7. One also observes that the two peaks of NP at 783 and 767 representing the catecholic ring breathing mode appear at 774 and $750 \mathrm{~cm}^{-1}$ in the inclusion complex. This observation corroborate the assignment of these two bands in the NP- $\beta C D$ complex, nonetheless one might argue that the peak at $750 \mathrm{~cm}^{-1}$ may originate from CB7 as well. The presence of the peak at $1605 \mathrm{~cm}^{-1}$ is a further confirmation of formation of inclusion complex between NP and CB7. A greater change in polarizability is associated with the breathing mode of the catecholic ring as the size of the ring changes considerably with vibrations.

The FT-Raman spectrum of NP- $\beta$ CD-18C6 freeze dried complex is shown in Fig. 6. The most prominent bands are those of $\beta C D$ which were slightly shifted in position. Interestingly, the $\mathrm{NH}_{2}$ bending vibration appears in the same position as in the neat NP solid. The aromatic ring breathing bands appear at the same wavenumbers as in the binary NP- $\beta C D$ complex at 773 and $755 \mathrm{~cm}^{-1}$ possibly because they are experiencing similar environment. The two bands of $18 \mathrm{C} 6$ at 1493 and $1472 \mathrm{~cm}^{-1}$ appear at 1469 and $1450 \mathrm{~cm}^{-1}$ in NP- $\beta C D-18 C 6$ inclusion complex. We also examined here the range of wavenumbers $2500-3500 \mathrm{~cm}^{-1}$ in more details. The results in Fig. 7 show that bands corresponding to $18 \mathrm{C} 6$ are all vanished in this region. The presence of strong intermolecular interactions might be responsible for such an observation suggesting that 18C6 is clearly involved in bonding with NP and the cyclodextrin.

Fig. 6 also shows the Raman spectrum of NP- $\beta C D-C B 7$ complex which as expected contains bands related to $\beta \mathrm{CD}$ and CB7. Interestingly, the region $500-900 \mathrm{~cm}^{-1}$ is dominated by CB7 bands. The carbonyl stretching vibration is located at 1749 $\mathrm{cm}^{-1}$. Surprisingly, the catechol ring breathing bands, which were present in all spectra, have completely disappeared in this spectrum. These observations may indicate that the spectrum of 


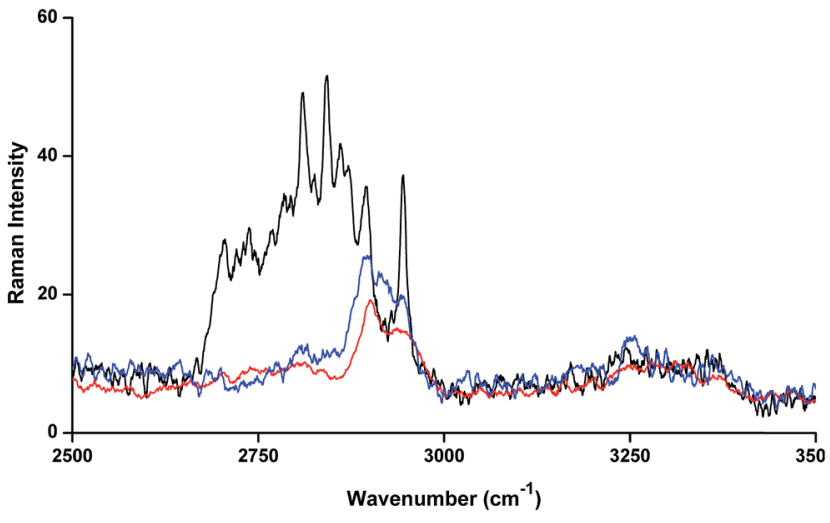

Fig. 7 FT-Raman spectra of $\beta C D$ (red line), $18 C 6$ (black line) and NP$\beta C D-18 C 6$ (blue line) freeze dried complex.

NP- $\beta C D-C B 7$ is not merely an overlap of binary complexes. The Raman spectrum of this species is complex due to the overlap of peaks of the components of the ternary mixture in most of the regions and this made the interpretation challenging. Nevertheless, one can conclude that there is clear indication for the formation of ternary complexes.

\section{Powder X-ray diffraction}

Powder X-ray diffraction (PXRD) is a sensitive technique usually used to investigate the crystal packing of hosts, guests and their inclusion complexes. In this work we used PXRD to look into the crystalline structures of NP, the three hosts and their respective inclusion complexes. The diffraction patterns of the pure solids of the guest and the hosts are presented in Fig. S4. $\dagger$ The PXRD patterns of the as-received $\beta C D$ consist of distinct diffraction peaks with $2 \theta$ values near 9 and $13^{\circ}$ in addition to other minor peaks at values of $2 \theta>13^{\circ}$. These features are known to characterize the cage type packing structure of $\beta \mathrm{CD}$ where the cavity of each $\beta C D$ is blocked by other neighboring $\mathrm{CD}$ molecules. ${ }^{51,58,59,61-63} 18 \mathrm{C} 6$ shows characteristic signals with $2 \theta$ in the range $15-25^{\circ}$ with the most intense peaks located at $2 \theta 15,20$, 24 and $25^{\circ}$. In case of CB7, the PXRD pattern exhibits halo structures which characterize it as a clear amorphous structure. $\mathrm{NP}$ is also crystalline material with characteristic peaks between $2 \theta \approx 15-30^{\circ}$. The most intense peaks in case of NP are observed at $2 \theta$ values $15,16,24,25$ and $26^{\circ}$.

The PXRD patterns of binary complexes are presented in Fig. 8. Careful examination of the patterns shown in this figure reveals the fact that these patterns are different from the starting material. They are also different from the physical mixtures obtained by mixing the starting materials in equimolar quantities in a pestle and mortar (data not shown). It worth noting here that the physical mixtures of starting materials exhibit only overlapped patterns of the original compounds. This indicates that inclusion complexes between NP and these hosts do not form by merely mixing them. The PXRD patterns of NP- $\beta$ CD complex show unique $2 \theta$ values at 10.5 and $12.5^{\circ}$ and minor diffractions at higher $2 \theta$ values. At higher $2 \theta$ values the peaks became also broader due to the
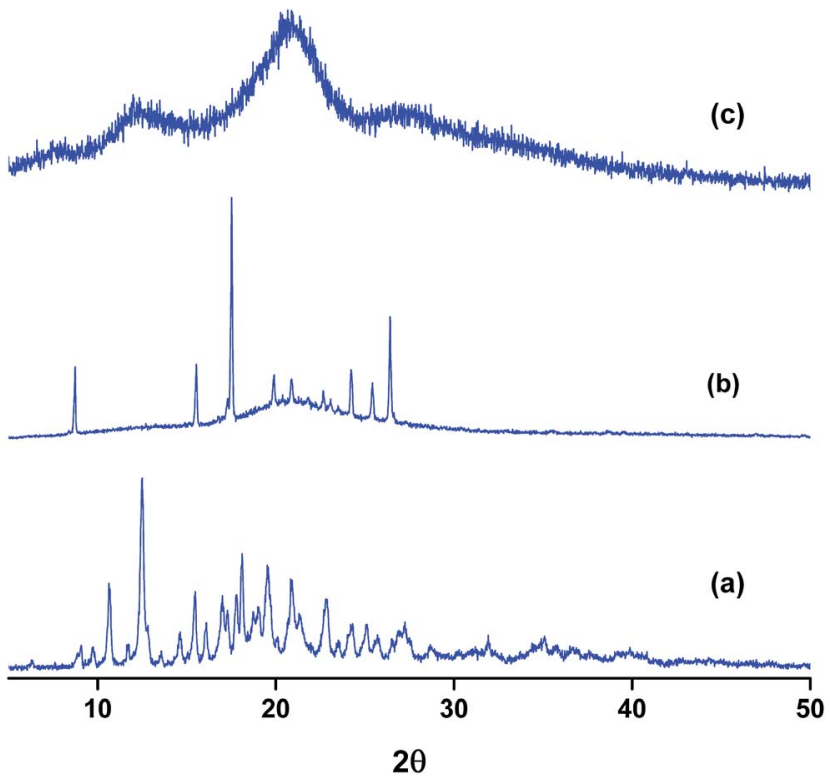

Fig. 8 PXRD patterns of binary complexes of NP with (a) $\beta C D$ (b) $18 C 6$ (c) CB7.

possible formation of partially amorphous phase. Similar results have been reported for the interaction of $\beta \mathrm{CD}$ with various guests. ${ }^{51,58,59,61-63}$

The complex between 18C6 and NP PXRD patterns are also shown in Fig. 8. These reflections are characterized by the formation of a broad halo pattern indicative of the amorphous nature of the material. However, distinct sharp peaks at $2 \theta$ values $\approx 9,15.5,17.5,24.0,25.5$ and $26.5^{\circ}$ are observed together with other minor reflections. Some of these peaks coincide with those present in the diffraction patterns of pure NP and 18C6 solids with the exception of the peak at $9^{\circ}$ which is absent from the PXRD patterns of both compounds. The initial evaluation of these results leads to the formation of an amorphous complex with the presence of uncomplexed material. However it is worth mentioning here that recording of PXRD runs for the freeze dried NP-18C6 samples was challenging as the complex starts to absorb humidity and become wet. Therefore, further investigation of this complex is required, probably the isolation of crystals suitable for single crystal analysis might cast better understanding of the packing and interactions in these complexes.

The diffraction patterns of NP-CB7 on the other hand exhibited halo shaped signatures declaring the formation of an amorphous solid complex. Moreover, the diffraction patterns of the ternary complexes in both cases, NP- $\beta \mathrm{CD}-18 \mathrm{C} 6$ and NP$\beta C D-C B 7$ are dominated by an amorphous structure as shown in Fig. 9. Unexpectedly, NP- $\beta \mathrm{CD}-\mathrm{CB} 7$ pattern is found to contain sharp peaks at $2 \theta$ values $10,14.5,19.5$ and 20 on top of the halo structures suggesting the involvement of a crystalline material. These observations may be due to the simultaneous formation of more than one complex. It should be mentioned here that the four peaks observed for NP- $\beta \mathrm{CD}-\mathrm{CB} 7$ are similar to those found in the NP- $\beta C D$ complex PXRD patterns. However, the amorphous signature is different than those observed for CB7 and NP-CB7 patterns. 

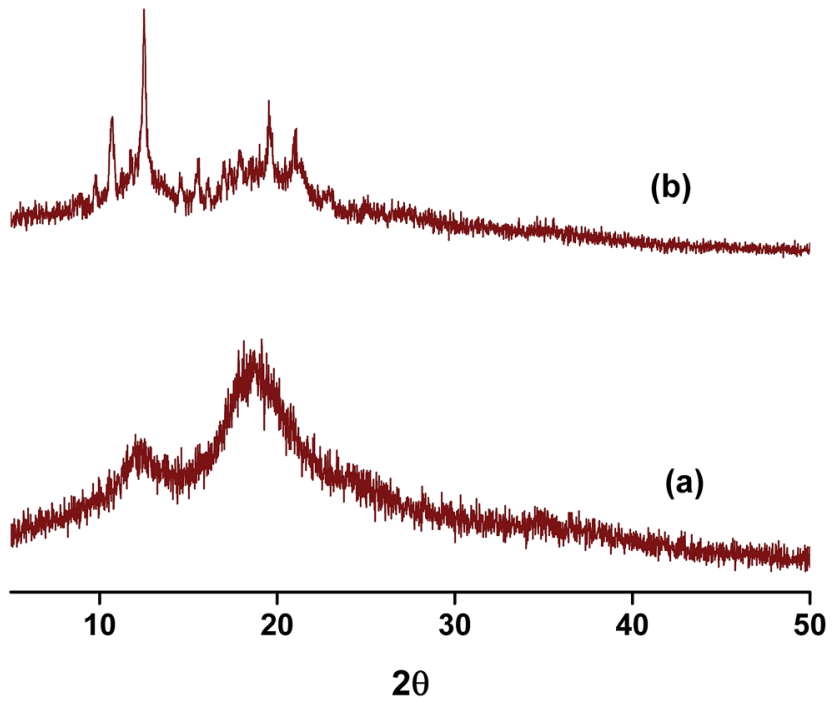

Fig. 9 PXRD patterns of ternary complexes of $N P-\beta C D$ with (a) $18 C 6$ (b) CB7.

\section{NMR spectroscopy}

To further elucidate the interactions between NP and the three host molecules ${ }^{1} \mathrm{H}$-NMR spectra were obtained. The individual protons were assigned according to the chemical structures presented in Scheme 1. The ${ }^{1} \mathrm{H}$-NMR spectra of NP in presence of 18C6 and $\beta C D$ exhibited notable shifts in some of the protons as a result of shielding of $\beta C D$ inner cavity protons and deshielding of guest protons. In this work, to characterize the complexation of NP with the two hosts, 18C6 and $\beta \mathrm{CD}$, we recorded 2D-ROESY spectra of the complexes in $\mathrm{D}_{2} \mathrm{O}$. Fig. 10 represents a typical expanded 2D-ROESY spectrum where F1 dimension corresponds to the signals assigned to protons of $\beta \mathrm{CD}$ and 18C6, while F2 here is focused on the aromatic region

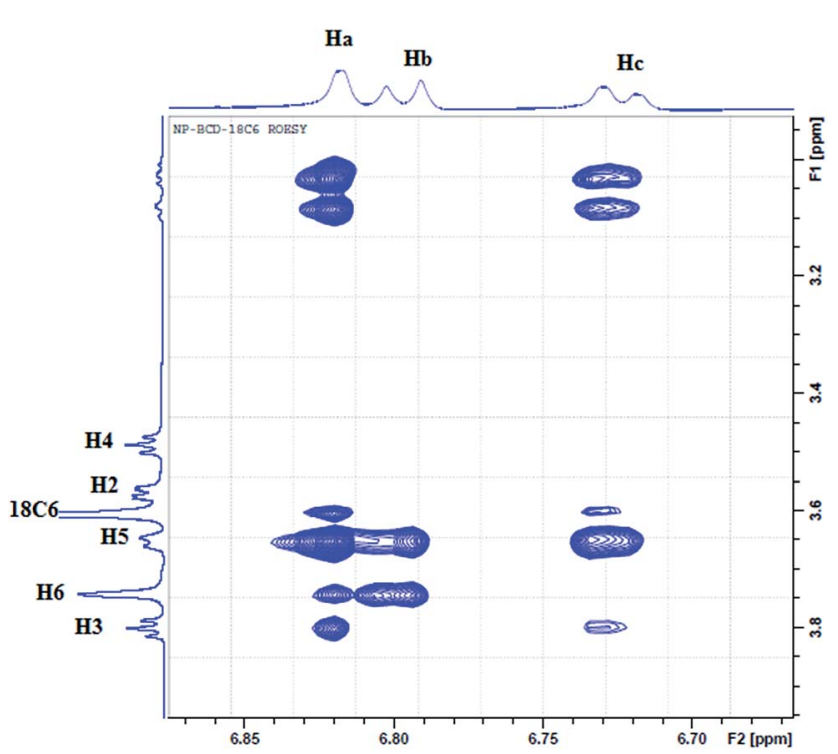

Fig. 10 The contour plot of 2D-ROESY of NP- $\beta C D-18 C 6$ inclusion complex. The assignment of signals is given according to Scheme 1. of NP. Clearly, intense cross-peaks are observed for the correlation of $\mathrm{H} 3, \mathrm{H} 5$ and $\mathrm{H} 6$ of $\beta \mathrm{CD}$ with those of NP. It can be inferred from these results that protons Ha and Hc on NP are in spatial proximity to protons $\mathrm{H} 3$ and $\mathrm{H} 5$ of the cyclodextrin. Interestingly, proton $\mathrm{Hb}$ on NP exhibit intense cross-peaks with both $\mathrm{H} 5$ and $\mathrm{H} 6$ but not with $\mathrm{H} 3$. Moreover, less intense but observable cross-peaks were observed for the interaction of 18C6 with protons Ha and Hc on NP. These results are consistent with the deep encapsulation of the catecholic moiety into the hydrophobic nanocavity of $\beta \mathrm{CD}$ through the secondary hydroxyl rim. The complex is further stabilized by interaction of the ammonium group of NP with 18C6 which secure the guest into the host's cavity.

\section{Molecular dynamics}

Molecular dynamic simulations were performed on NP complexes with the three hosts as well as on ternary complexes. The complexes were immersed in a box of water and calculations were performed for 15-20 ns at a pressure and temperature of 1 atm and $300 \mathrm{~K}$, respectively. The average root mean square deviations (RMSDs) for all binary complexes are shown in Fig. S5. $\dagger$ Clearly, all complexes reach stability within short time ( $<1 \mathrm{~ns}$ ). The average values obtained over trajectories after stabilization are summarized in Table 2. Evidently, these complexes are quite stable in aqueous solutions except for NP$\beta C D-C B 7$. NP- $\beta C D-C B 7$ complex is formed by inserting the aromatic group into $\beta C D$ cavity while leaving the side chain bearing the amine group to interact with CB7. As shown in Fig. S5c $\dagger$ NP forms a strong complex with $\beta \mathrm{CD}$ as evident from the stable trajectories of NP- $\beta C D$ complex compared to NP$\beta C D-C B 7$ complex. Unexpectedly, we observed that CB7 starts to move away from the other two molecules following $4 \mathrm{~ns}$ of stability. Interestingly when we run a similar simulation with the aromatic ring of NP inserted into CB7 we observed that NP is completely taken into CB7 and $\beta C D$ was pushed away. These results suggest the possible coexistence of binary and ternary complexes.

Additionally, we monitored the radius of gyration $\left(r_{\mathrm{gyr}}\right)$ of the guest, host and their corresponding inclusion complexes during the simulation time. The values obtained are summarized in Table 2. It can be observed from this table that $r_{\mathrm{gyr}}$ for all complexes is close to that of the host. Moreover, the values of

Table 2 Average values of RMSD and radius of gyration obtained from molecular dynamics trajectories for the various species

\begin{tabular}{lll}
\hline Compound & RMSD $(\AA)$ & $r_{\text {gyr }}(\AA)$ \\
\hline NP & $1.15 \pm 0.48$ & $2.75 \pm 0.03$ \\
18C6 & - & $3.42 \pm 0.05$ \\
BCD & $1.85 \pm 0.45$ & $5.91 \pm 0.07$ \\
CB7 & $0.46 \pm 0.12$ & $5.49 \pm 0.02$ \\
NP-18C6 & $2.53 \pm 0.48$ & $3.99 \pm 0.05$ \\
NP- $\beta C D$ & $1.77 \pm 0.33$ & $5.67 \pm 0.07$ \\
NP-CB7 & $0.65 \pm 0.14$ & $5.27 \pm 0.02$ \\
NP-18C6- $\beta C D$ & $0.99 \pm 0.23$ & $5.95 \pm 0.14$ \\
NP-CB7- $\beta C D$ & - & -
\end{tabular}


$r_{\text {gyr }}$ for the inclusion complexes are lower than the sum of the individual hosts and guest. This provides additional evidence for the stability of these complexes.

We also performed hydrogen bond analysis for all the complexes using the modules of Schrodinger software. The results collected in Fig. S6 $\dagger$ show that a number of hydrogen bond interactions are contributing to the stability of the complexes during the simulation time. NP- $\beta C D$ complex is stabilized by the presence of 1-3 hydrogen bonds (Fig. S6a $\dagger$ ). NP size is suitable for insertion of the catechol group into the cavity of $\beta C D$ via either the wider or narrower rim of the CD. Introduction of the catechol group through the wider rim, however, produced a more stable inclusion complex. Additionally, the complex formed by inserting the aromatic ring from the narrower rim shows stable trajectories for about 9 ns out of the total simulation time of $15 \mathrm{~ns}$. Placing primary amine and $\mathrm{OH}$ groups at the entrance of the cyclodextrin allow for strong intermolecular interactions such as hydrogen bonding and dipole-ion interaction between these groups and the secondary hydroxyl groups that enfold the wider rim.
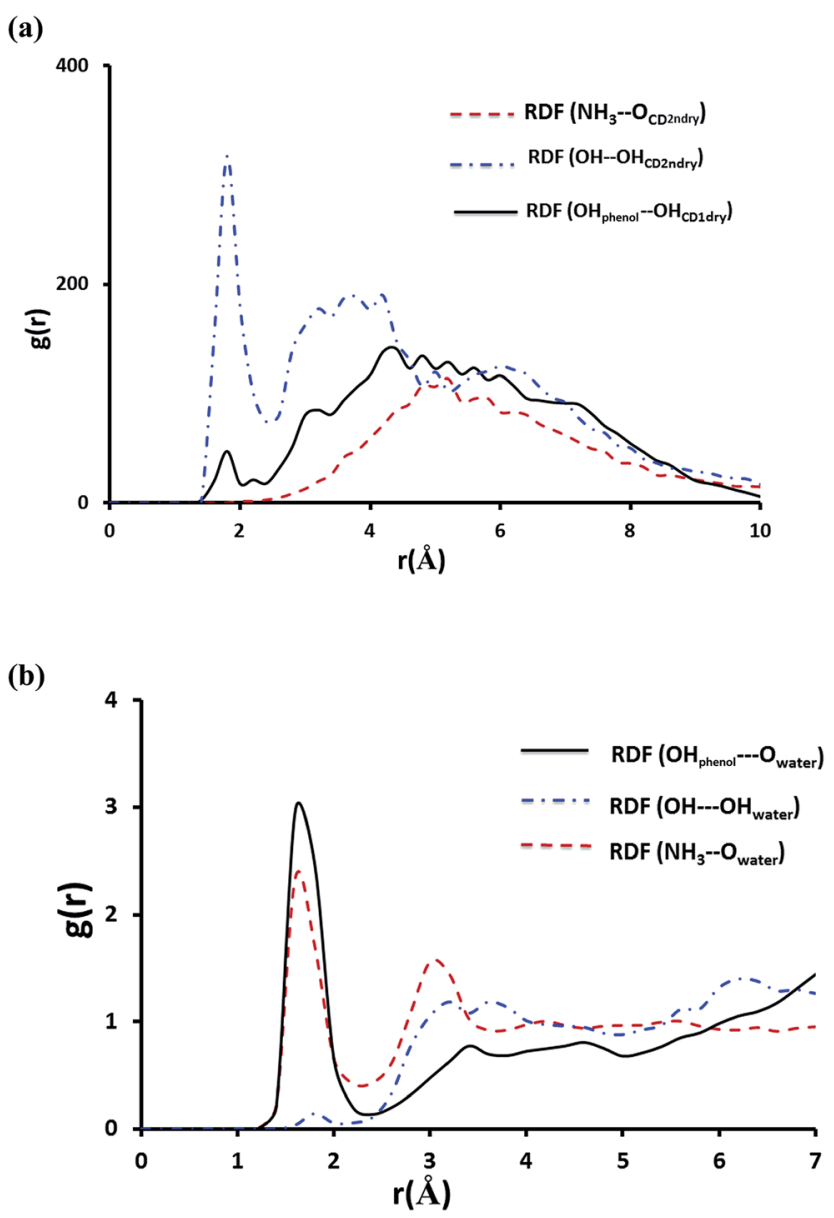

Fig. 11 The RDF of hydrogen bonding interactions for NP- $\beta C D$ complex plotted as a function of separation distance $r$ (in $\AA$ ) between donor and acceptor (a) interaction of NP with host (b) interaction of NP with water. These plots were obtained from MD trajectories after equilibration of the inclusion complex.
To shed more light on the interaction of NP with $\beta C D$ we further obtained the radial distribution function (RDF), $g_{(r)}$, for the center of mass of NP relative to that of the host. The result in Fig. $\mathrm{S} 7 \dagger$ shows a strong sharp peak at $0.2 \AA$ clearly suggesting that NP is inserted deeply into the cavity of $\beta C D$. This position likely allows stabilization of NP inside the cavity by strong hydrogen bond interaction as shown by the strong sharp peak at $\sim 1.8 \AA$ in Fig. 11a representing interaction of $\mathrm{OH}$ with the secondary hydroxyl groups of the CD. Also one observes a minor hydrogen-bond contribution from the phenolic OH of NP with the primary hydroxyl groups of $\mathrm{CD}$. On the other hand, the protonated primary amine exhibited no noticeable interaction with the secondary hydroxyl groups of the cyclodextrin. From these results and by inspection of snapshots from the simulation it is clear that the protonated amine (highly polar group) remains solvated by water molecules outside the cavity of the cyclodextrin.

Fig. 11b shows the RDFs for the interaction of $\mathrm{NH}_{3}{ }^{+}, \mathrm{OH}$ and the phenolic groups with water molecules. The maximum at $r \sim$

(a)

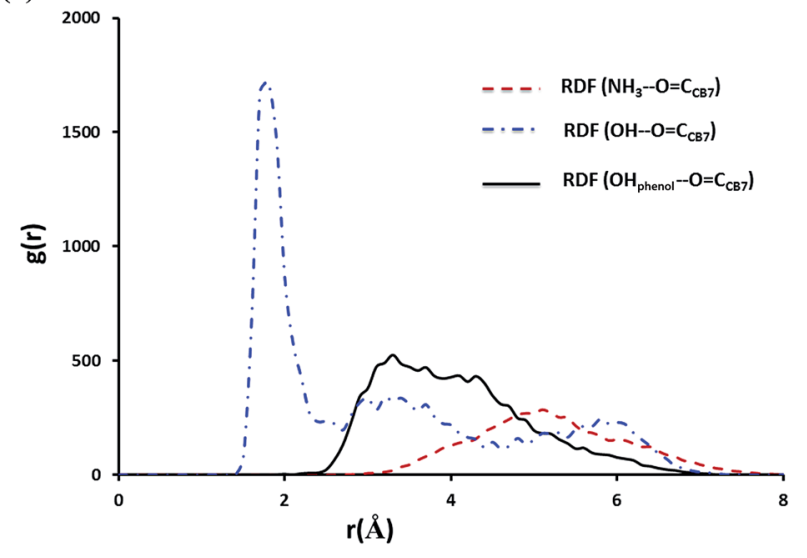

(b)

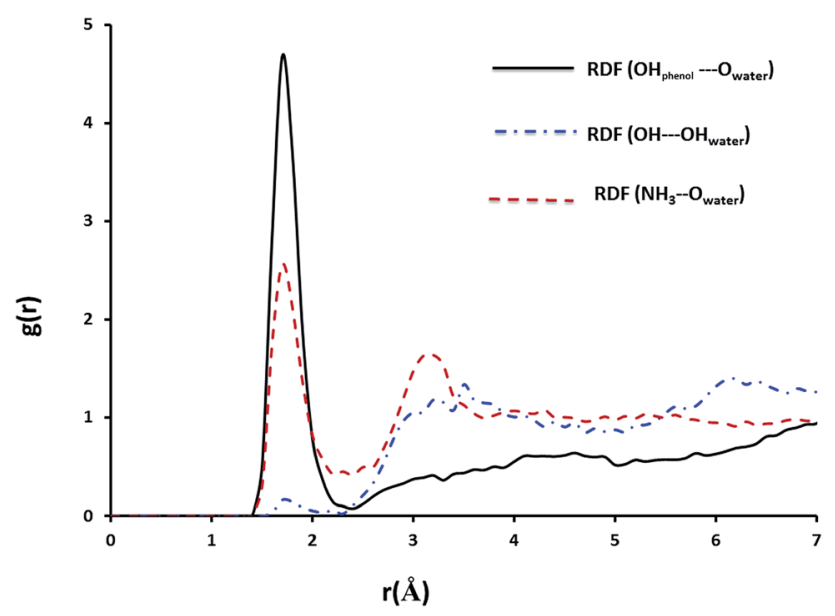

Fig. 12 The RDF of hydrogen bonding interactions for NP-CB7 complex plotted as a function of separation distance $r$ (in $\AA$ ) between donor and acceptor (a) interaction of NP with host (b) interaction of NP with water. These plots were obtained from MD trajectories after equilibration of the inclusion complex. 
1.8 ̊ correspond to the first hydration shell indicating that the amino-group and the two phenolic substituents on the aromatic ring are strongly involved in hydrogen bonding with water molecules. It can be inferred from these results that $\mathrm{NH}_{3}{ }^{+}$ remains outside the cavity and NP catechol moiety is inserted inside the nanocavity with the two phenolic groups protruding from the narrower rim and, therefore, exposed to water molecules.

In case of the inclusion complex of NP with CB7 it was observed that one hydrogen bond prevails till the end of the simulation, however, other weaker hydrogen bond interactions are also recorded (Fig. S6a $\dagger$ ). Let us now examine the RDFs describing hydrogen bonding of NP with CB7 and with water. The calculated RDFs are presented in Fig. 12. Obviously only the secondary $\mathrm{OH}$ group of NP forms a strong hydrogen bond with the $\mathrm{C}=\mathrm{O}$ groups on the portal of $\mathrm{CB7}$. Both $\mathrm{NH}_{3}{ }^{+}$and the phenolic moieties exhibit strong interaction with the water molecules as can be inferred from Fig. 11b.

As expected for the NP- $\beta$ CD-18C6 system Fig. 13 reveals the presence of hydrogen bond network as a result of interaction of NP with $\beta \mathrm{CD}$ and $18 \mathrm{C} 6$ simultaneously. Interestingly, $\beta \mathrm{CD}$ and

(a)

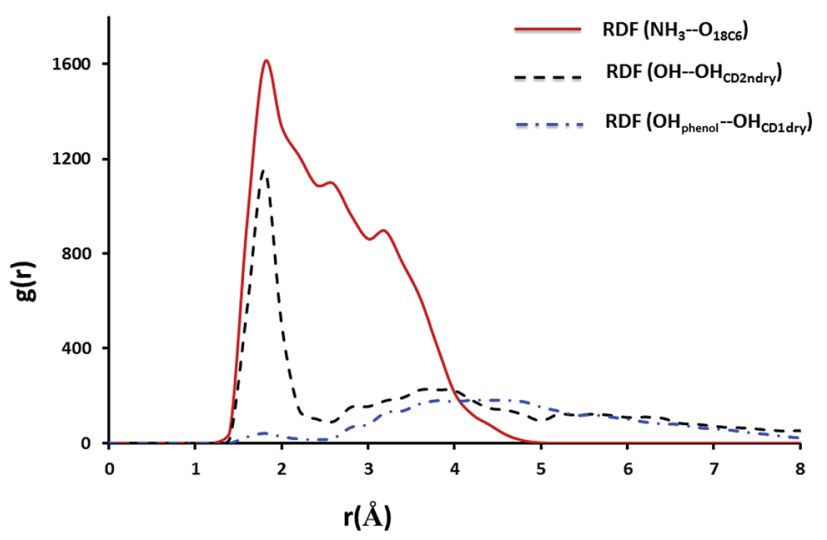

(b)

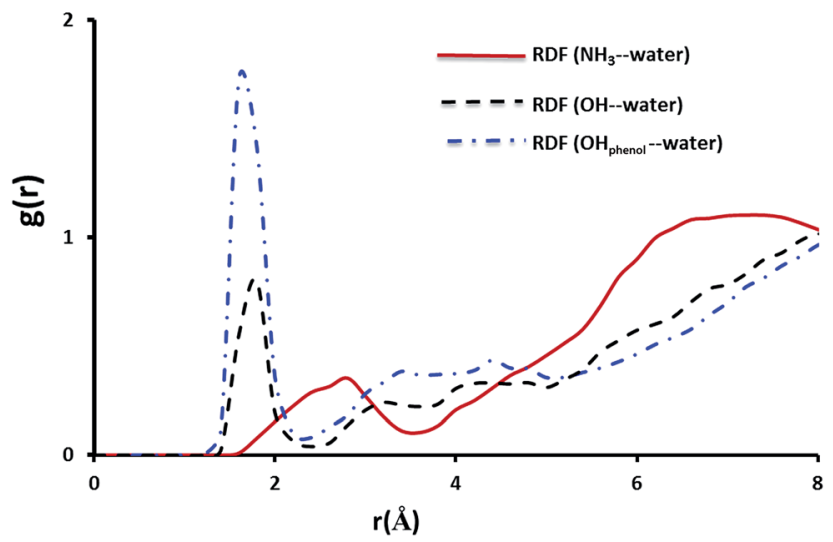

Fig. 13 The RDF of hydrogen bonding interactions for NP- $\beta C D-18 C 6$ complex plotted as a function of separation distance $r$ (in $\AA$ ) between donor and acceptor. (a) Represents interaction of NP with the two hosts. (b) Represents interaction of NP with water.
18C6 exhibited only one weak hydrogen bond that forms and break throughout the simulation time (Fig. S6b $\dagger$ ). The distance from the center of mass of NP to that of $\beta \mathrm{CD}$ is close to that observed for NP- $\beta$ CD system with the aromatic ring inside the cavity of the cyclodextrin (Fig. S8 $\dagger$ ). Here we also examined RDFs concerning the hydrogen bonding interactions in this ternary complex. As expected $\mathrm{NH}_{3}{ }^{+}$group interact strongly with the crown ether oxygen atoms as represented by the strong peak at $r \sim 1.8 \AA$ as presented in Fig. 13. Additional peaks are also observed for the amino group interaction with the crown ether at 2.5 and $3.4 \AA$ representing weaker hydrogen bonding interactions formed during the simulation.

The hydroxyl group of NP interacts strongly with the secondary hydroxyl groups on the cyclodextrin; however, the phenolic groups exhibited a very weak interaction with the hydroxyl groups at the narrow portal of the cyclodextrin. This may originate from the interaction of 18C6 with NP which may require tilting and moving the molecule up to achieve favorable positions for maximum intermolecular interactions.

The interaction of NP with water molecules in the ternary complex is represented by Fig. 13b. As expected the phenolic groups preserved their contacts with water as shown in this figure. However, the hydroxyl group of NP exhibited strong interaction with water compared to those observed in NP$\beta C D$ and NP-CB7 binary complexes. To interpret these results we obtained snapshots for the ternary complex during the simulation times. Representative snapshots are shown in Fig. S9. $\dagger$ We observed that due to the strong interaction between the amino group and the crown ether oxygen atoms NP molecule is dragged up into the cavity of the CD. This in turn moves the $\mathrm{OH}$ to the pocket between 18C6 and $\beta \mathrm{CD}$ where water molecules can enter to form a network of hydrogen bonds involving $\mathrm{OH}, \mathrm{CD}$ secondary $\mathrm{OH}$ groups and the crown ether. This leads to additional stabilization of this complex.

\section{Conclusion}

The fluorescence, ESI-MS, vibrational spectroscopy, ${ }^{1} \mathrm{H}-\mathrm{NMR}$ spectroscopy and PXRD data presented in this work reveal that NP forms stable inclusion complexes with the three hosts. The data also indicate that stable ternary complexes involving $\mathrm{NP}$ in presence of $18 \mathrm{C} 6 / \beta \mathrm{CD}$ and $\mathrm{CB} 7 / \beta \mathrm{CD}$ are formed. Molecular dynamic simulations of inclusion complexes in aqueous media have indicated that insertion of the aromatic ring into the cavity of $\beta C D$ and $C B 7$ is the most acceptable mechanism of the inclusion process. Moreover, the strong hydrogen bond interactions between hosts and the guest are responsible for the stability of these complexes. It would be tempting, however, to conclude that NP-18C6- $\beta \mathrm{CD}$ is a more stable complex compared to NP-CB7- $\beta C D$. While the inclusion of NP into the nanocavity of $\beta C D$ and $C B 7$ seems to be controlled by hydrophobic forces, hydrogen bonding and ion-dipole interactions plays significant role in stabilizing these compounds. This could be the main reason behind the tendency of these complexes to aggregate in solution. 


\section{Acknowledgements}

S. K. S. Al Burtomani acknowledges support from SQU. The technical support by Central Analytical and Applied Research Unit (CAARU) and Nanotechnology Center at SQU is highly appreciated.

\section{References}

1 E. Masson, X. Ling, R. Joseph, L. Kyeremeh-Mensah and X. Lu, RSC Adv., 2012, 2, 1213-1247.

2 Z. Miskolczy and L. Szló Biczó, Phys. Chem. Chem. Phys., 2014, 16, 20147-20156.

3 K. I. Assaf and W. M. Nau, Chem. Soc. Rev., 2015, 44, 394-418. 4 S. J. Barrow, S. Kasera, M. J. Rowland, J. Del Barrio and O. A. Scherman, Chem. Rev., 2015, 115, 12320-12406.

5 M. N. Shewale, D. N. Lande and S. P. Gejji, J. Mol. Liq., 2016, 216, 309-317.

6 S. Li, X. Miao, I. W. Wyman, Y. Li, Y. Zheng, Y. Wang, D. H. Macartney and R. Wang, RSC Adv., 2015, 5, 5611056115.

7 X.-D. Xiao, L. Shi, L.-H. Guo, J.-W. Wang and X. Zhang, Spectrochim. Acta, Part A, 2017, 173, 6-12.

8 J. Ma, F. Shi, D. Tian and H. Li, Chem.-Eur. J., 2016, 22, 13805-13809.

9 M. V. Rekharsky and Y. Inoue, Chem. Rev., 1998, 98, 18751918.

10 J. Szejtli, Chem. Rev., 1998, 98, 1743-1753.

11 G. W. Gokel, W. M. Leevy and M. E. Weber, Chem. Rev., 2004, 104, 2723-2750.

12 O. P. Kryatova, I. V. Korendovych and E. V. Rybak-Akimova, Tetrahedron, 2004, 60, 4579-4588.

13 K. M. Doxsee, P. E. Francis Jr and T. J. R. Weakley, Tetrahedron, 2000, 56, 6683-6691.

14 J. Zhou, J. Tang and W. Tang, TrAC, Trends Anal. Chem., 2015, 65, 22-29.

15 L. Escuder-Gilabert, Y. Martín-Biosca, M. J. MedinaHernández and S. Sagrado, J. Chromatogr. A, 2014, 1357, 223.

16 P. ̌̌ezanka, K. Navrátilová, M. Řezanka, V. Král and D. Sýkora, Electrophoresis, 2014, 35, 2701-2721.

17 G. Gübitz and M. G. Schmid, J. Chromatogr. A, 2008, 1204, 140-156.

18 G. K. E. Scriba, J. Sep. Sci., 2008, 31, 1991-2011.

19 I. W. Muderawan, T.-T. Ong and S.-C. Ng, J. Sep. Sci., 2006, 29, 1849-1871.

20 W. X. Huang, H. Xu, S. D. Fazio and R. V. Vivilecchia, J. Chromatogr. A, 2000, 875, 361-369.

21 T. Koide and K. Ueno, J. Chromatogr. A, 2001, 923, 229-239. 22 C. Zhang, W. X. Huang, Z. Chen and A. M. Rustum, J. Chromatogr. A, 2010, 1217, 4965-4970.

23 A. A. A. A. Elbashir and F. O. F. O. Suliman, J. Chromatogr. A, 2011, 1218, 5344-5351.

24 Q. Zhu, S. H. Heinemann, R. Schönherr and G. K. E. Scriba, J. Sep. Sci., 2014, 37, 3548-3554.

25 B. Minea, N. Marangoci, D. Peptanariu, I. Rosca, V. Nastasa, A. Corciova, C. Varganici, A. Nicolescu, A. Fifere, A. Neamtu,
M. Mares, M. Barboiu and M. Pinteala, New J. Chem., 2016, 40, 1765-1776.

26 S. Saha, T. Ray, S. Basak and M. N. Roy, New J. Chem., 2016, 40, 651-661.

27 T. Aree and S. Jongrungruangchok, Carbohydr. Polym., 2016, 140, 362-373.

$28 \mathrm{~J}$. Kicuntod, W. Khuntawee and P. Wolschann, J. Mol. Graphics Modell., 2016, 63, 91-98.

29 R. B. Pellegrino Vidal, G. A. Ibañez and G. M. Escandar, $R S C$ Adv. , 2015, 5, 20914-20923.

30 A. Arrais and P. Savarino, J. Inclusion Phenom. Macrocyclic Chem., 2009, 64, 73-81.

31 M. I. Sancho, S. A. Andujar, R. D. Porasso and R. D. Enriz, J. Phys. Chem. B, 2016, 120, 3000-3011.

32 I. Terekhova, R. Kumeev, G. Alper, S. Chakraborty, H. PérezSánchez and E. Núñez-Delicado, RSC Adv., 2016, 6, 4956749577.

33 N. F. A. F. A. Dsugi, A. A. A. Elbashir and F. E. O. O. Suliman, Spectrochim. Acta, Part A, 2015, 151, 360-367.

34 F. O. O. Suliman, A. A. A. Elbashir and O. J. J. Schmitz, J. Inclusion Phenom. Macrocyclic Chem., 2015, 83, 119-129.

35 B. Varghese, S. N. Al-Busafi, F. O. Suliman and S. M. Z. AlKindy, Spectrochim. Acta, Part A, 2015, 136, 661-671.

36 S. Alavi, K. Udachin, I. Moudrakovski, R. Susilo and J. a Ripmeester, J. Chem. Eng. Data, 2011, 60, 389-397.

37 T. D. E. Hugh and C. Hemmings, Pharmacology and Physiology for Anesthesia: Foundations and Clinical Applications, Elsevier Saunders, 2013.

38 D. A. Schwinn, in Cardiac Anesthesia: Principles and Clinical Practice, ed. J. G. R. Fawzy, G. Estafanous and Paul G. Barash, Lippincott Williams \& Wilkins, Philadelphia, 2nd edn, 2001, p. 84.

39 A. Antony Muthu Prabhu, V. K. Subramanian and N. Rajendiran, Spectrochim. Acta, Part A, 2012, 96, 95-107.

40 N. Rajendiran, T. Mohandoss and J. Thulasidasan, J. Fluoresc., 2014, 24, 1003-1014.

41 B. Bernardo-Maestro, F. López-Arbeloa, J. Pérez-Pariente and L. Gómez-Hortigüela, J. Phys. Chem. C, 2015, 119, 2821428225.

42 T. Álvaro-Muñoz, F. López-Arbeloa, J. Pérez-Pariente and L. Gómez-Hortigüela, J. Phys. Chem. C, 2014, 118, 3069-3077.

43 X. Y. Gong and P. C. Hauser, J. Chromatogr. A, 2005, 1094, 196-199.

44 D. W. Armstrong, L. W. Chang and S. S. C. Chang, J. Chromatogr. A, 1998, 793, 115-134.

45 J. J. P. Stewart, J. Mol. Model., 2013, 19, 1-32.

46 K. J. Bowers, E. Chow, H. Xu, R. O. Dror, M. P. Eastwood, B. A. Gregersen, J. L. Klepeis, I. Kolossvary, M. A. Moraes, F. D. Sacerdoti, J. K. Salmon, Y. Shan and D. E. Shaw, in Proceedings of the ACM/IEEE conference on Supercomputing (SC '06), Tampa, Florida, 2006, p. 84.

47 D. E. Shaw, Desmond Molecular Dynamics System, New York, NY, 2009.

48 U. Essmann, L. Perera, M. Berkowitz, T. Darden, H. Lee and L. Pedersen, J. Chem. Phys., 1995, 103, 8577-8593.

49 T. Koide and K. Ueno, J. Chromatogr. A, 2001, 923, 229-239. 
50 W. S. Jeon, K. Moon, S. H. Park, H. Chun, Y. H. Ko, Y. Lee, E. S. Lee, S. Samal, N. Selvapalam, M. V Rekharsky, D. Sobransingh, Y. Inoue, A. E. Kaifer, K. Kim, W. S. Jeon, K. Moon, S. H. Park and H. Chun, J. Am. Chem. Soc., 2005, 2, 12984-12989.

51 T. Uyar, M. A. Hunt, H. S. Gracz and A. E. Tonelli, Cryst. Growth Des., 2006, 6, 1113-1119.

52 T. J. Brett, J. M. Alexander and J. J. Stezowski, J. Chem. Soc., Perkin Trans. 2, 2000, 6, 1095-1103.

53 T. J. Brett, M. Alexander and J. J. Stezowski, J. Chem. Soc., Perkin Trans. 2, 2000, 6, 1105-1111.

54 P. Jackson and M. I. Attalla, Rapid Commun. Mass Spectrom., 2010, 24, 3567-3577.

55 M. I. Sancho, S. Andujar, R. D. Porasso and R. D. Enriz, J. Phys. Chem. B, 2016, 120, 3000-3011.

56 S. Pande, S. Jana, A. K. Sinha, S. Sarkar, M. Basu, M. Pradhan, A. Pal, J. Chowdhury and T. Pal, J. Phys. Chem. $C$, 2009, 113, 6989-7002.
57 S. Pande, S. Jana, A. K. Sinha, S. Sarkar, M. Basu, M. Pradhan, A. Pal, J. Chowdhury and T. Pal, J. Phys. Chem. $C$, 2009, 113, 6989-7002.

58 L. Cunha-Silva and J. J. C. Teixeira-Dias, New J. Chem., 2005, 29, 1335-1341.

59 L. Cunha-Silva and J. J. C. Teixeira-Dias, New J. Chem., 2004, 28, 200-206.

60 Y. Chen, A. Klimczak, E. Galoppini and J. V Lockard, RSC Adv., 2013, 3, 1354-1358.

61 D. Mentzafos, I. M. Mavridis, G. Le Bas and G. Tsoucaris, Acta Crystallogr., Sect. B: Struct. Crystallogr. Cryst. Chem., 1991, 47, 746-757.

62 D. Mentzafos, I. M. Mavridis and M. B. Hursthouse, Acta Crystallogr., Sect. C: Cryst. Struct. Commun., 1996, 52, 12201223.

63 F. Kayaci and T. Uyar, J. Agric. Food Chem., 2011, 59, 1177211778. 